\title{
Immune to the facts
}

\section{A flawed paper on autism compromised MMR vaccination and public health.}

\author{
MMR Science \& Fiction: Exploring \\ A Vaccine Crisis \\ by Richard Horton \\ Granta: 2004. 220 pp. $£ 7.99$ \\ MMR and Autism: What Parents \\ Need to Know \\ by Michael Fitzpatrick \\ Routledge: 2004. 232 pp. £45, \$75(hbk); \\ £14.99, \$23.95 (pbk)

\section{Michael B. A. Oldstone}

The measles virus is remarkably contagious, infecting more than $95 \%$ of susceptible humans exposed to it. About 1 in 1,000 people infected requires hospitalization and may become permanently disabled, and 1 in 300,000 infected with measles develops a progressive neurological disorder, subacute sclerosing panencephalitis, which invariably causes death.

But along with smallpox, yellow fever and poliomyelitis, measles is remarkably well controlled by vaccination. Before routine measles vaccination in the United States, some 4,000,000 people a year contracted the disease; widespread vaccination has brought this number down to less than 40. Other countries in which $95 \%$ of the population are vaccinated - the proportion believed to provide 'herd immunity', which blocks the transmission of measles - have experienced similar declines in cases. However, coverage in some regions of Africa is less than $50 \%$ of the population, and there are still some 40,000,000 infections each year, causing more than 600,000 deaths.

These figures highlight the amazing achievements of measles vaccines and the need for mandatory vaccination to maintain this record of success. Nonetheless, the antivaccination sentiment, which began after Edward Jenner first used cowpox vaccine to prevent smallpox, continues today. The reasons are complex and multifactorial but often arise from basic libertarianism or individualism, along with people's desire to stop the government and public-health bodies having so much control over them and their children. Others consider vaccines harmful or refuse to face even the minor risk of sideeffects. Many people are misled and others misinformed.

This was the backdrop to a recent attack in Britain on the combined measles, mumps and rubella (MMR) vaccine by some parents with autistic children, by news reporters and by some in the British government. As a result, MMR vaccination coverage sank to $85 \%$ or below in Britain, soon to be followed by outbreaks of measles and, sometimes, devastating after-effects. So the publication

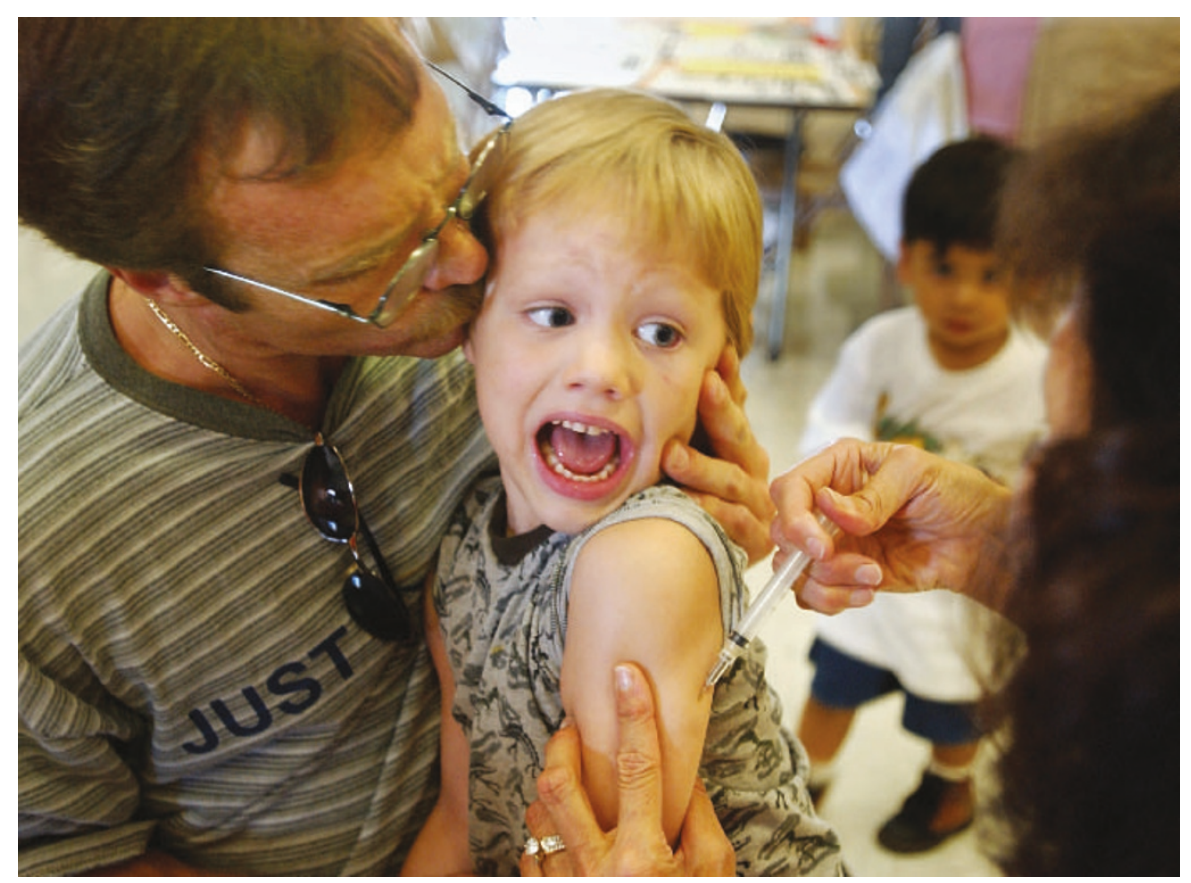

Afraid of needles? Fewer children receive the MMR vaccine since scare stories linked it to autism.

of two books reviewing autism and the search for an environmental cause, especially the MMR vaccine, are particularly timely.

MMR Science \& Fiction by Richard Horton, editor of The Lancet, and MMR and Autism by Michael Fitzpatrick, a general practitioner of medicine and parent of an autistic child, both make the case that the MMR vaccine is safe and is not associated with autism. Both books provide the background to help readers understand the events in Britain and the players involved, as well as the evidence that supports their conclusion that the vaccine is safe.

Autism, first recognized in the 1940s, results in children having an inability to relate to themselves or to people and situations. Its cause is unknown. However, in 1998, The Lancet, with Horton as editor, published a paper by the gastroenterologist Andrew Wakefield and colleagues at the Royal Free Hospital in London that linked autism and the MMR vaccine. According to the paper, of 12 children who had both autism and chronic enterocolitis (bowel disease), eight had been given the vaccine and one had a measles infection before the onset of autism. No virological evidence was provided of the measles infection, nor was there any stringent epidemiologic evidence to link it, or other events, to the autism, and there was no control group of children. Fuelled by concern and self-interest, some of the authors, journalists and parents of autistic children went to the newspapers, citing the article as proof of a connection between MMR and autism. The publicity sparked a public movement against vaccination that quickly grew out of control.

Of the two books, Fitzpatrick's provides the more thorough and detailed account of the events as they unfolded. It includes a critical evaluation of the flawed paper in The Lancet and discusses autism in greater depth. This book is a good read.

Horton's book contains similar information but focuses primarily on the events, complications and failures that followed the publication in The Lancet. As an antidote, he suggests that an ombudsman group of scientists and laymen should evaluate such controversial findings to prevent the spread of misinformation. He also describes the profiteers: journalists and publicists, medical practitioners who received fees from lawyers representing the parents of the autistic children, and physicians and scientists who were compensated by pharmaceutical houses, biotech companies and government officials. Horton attributes the public mistrust to these sources. These financial conflicts of interest, along with questions over informed consent for the children, resulted in several, but not all, of the authors retracting the paper six years after its publication. Horton does not deny his own responsibility, stating that if he knew in 1998 what he knows now, The Lancet "would not have published the part of the paper that related to MMR".

But the crux of the issue is missing from 
Horton's book. Without firm evidence of measles infection or of the measles virus in the MMR vaccine being involved in disease, why was the claim of an association between autism, the measles virus and the MMR vaccine placed in the results section of the paper? In Horton's defence, the same issue of The Lancet published a commentary pointing out the defects in Wakefield's paper, but the question remains: why did The Lancet open Pandora's box?

Good science demands objectivity based on experimental or clinical evidence that is reliable and reproducible. Subjective opinion is not proof and has no place in the peer-reviewed literature. Indeed, as quoted in Horton's book, Britain's chief medical officer, Liam Donaldson, stated: "If the paper had never been published, then we wouldn't have had the controversy, we wouldn't have had the seed of doubt sown in parents' minds which has caused a completely false loss of confidence in a vaccine that has saved millions of children's lives around the world." Donaldson is correct.

What's more, the continued focus of Wakefield, journalists and parents of autistic children on autism's link with measles, coupled with the complacency of a public that has been shielded from the horrors of uncontrolled infections, has supported a continued antivaccination movement. This has had a regrettable influence on the public and the political establishment concerning measles and autism specifically, and vaccination in general.

Michael B. A. Oldstone is head of the Division of Virology, Department of Neuropharmacology,

The Scripps Research Institute, 10550 North Torrey Pines Road, La Jolla, California 92037, USA.

\section{Across the border}

\author{
Alien Species and Evolution: The \\ Evolutionary Ecology of Exotic \\ Plants, Animals, Microbes, and \\ Interacting Native Species \\ by George W. Cox \\ Island Press: 2004.377 pp. $\$ 75$ (hbk), \\ $\$ 40$ (pbk)
}

\section{David M. Lodge}

While some governments are preoccupied with preventing border crossings by terrorists, thousands of alien species (those from other regions or continents) continue to be allowed free entry into most countries of the world. Some of these alien species are certain to cause great harm to the environment, native species, national economies and human health, as other species have done in the past. In this era of supposedly great attention to border security, how do the aliens keep on getting through?

Commercial markets in live food, pets,

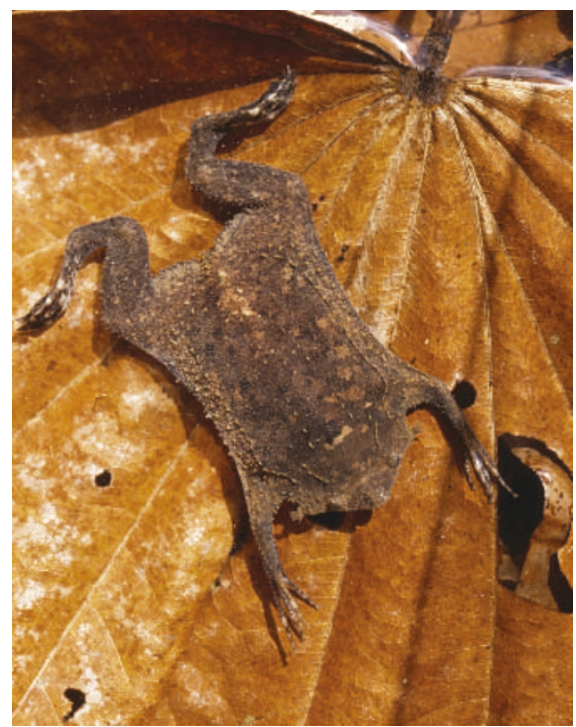

Alien invader: the Surinam toad was introduced to Australia from its native South America.

horticulture and aquaculture intentionally import a wide range of alien species into many countries every year, with little government supervision and often no analysis of the attendant environmental, health and financial risks. Thousands of other species hitch-hike on legitimate cargo or the ships, planes and other vehicles that carry them.

Most of these aliens will do little or no harm, but some will cause irreversible damage. Recent examples include the North American grey squirrel in Europe; the Asian longhorned beetle in North America; the Northern Pacific seastar and the Surinam toad in Australia; the European red deer in South America; the South American water hyacinth in Africa; and the Australian brown tree snake on Pacific islands. Changing patterns of trade mean that increasing numbers of alien species come from previously isolated regions.

The environmental and economic damage wrought by alien species includes the extinction of native species, and large alterations in ecosystem characteristics, such as nutrient fluxes and fire frequency. Charles Elton anticipated many of these environmental effects in his 1958 book The Ecology of Invasions by Animals and Plants. Indeed, it often seems that invasion biology (a recent addition to the list of biological subspecialisms) is little more than Elton redux. However, in Alien Species and Evolution, George Cox extends traditional concerns about alien species beyond the ecological theatre, and puts the evolutionary play on centre stage. His main concern is genetic change, both in alien species, which are subject to founder effects and new selection pressures, and in native species, as they experience new selection pressures imposed by the aliens.

This extremely readable book is aimed primarily at students and researchers. Cox provides comprehensive coverage of alien species in different taxonomic groups and in different habitats: terrestrial, freshwater and marine. Replete with examples and abundantly referenced, the book provides an excellent evolutionary synthesis. Cox occasionally makes extended forays beyond alien species, but only to illustrate the broader context in which adaptation and counteradaptation occur. The book is therefore also a good introduction to the broader intellectual landscape of evolution and global environmental change.

The coverage of hybridization between alien and native species may be particularly useful, as many readers might not have encountered it before. The interaction between hybridization and polyploidy has already produced a number of new terrestrial plant species from ancestral species, for instance when European salsifies (Tragopogon) were introduced into North America. Hybridization and introgression have also been common in freshwater fishes, crustaceans and molluscs, as human interventions have brought closely related species together. This often results in the loss of native species as an evolutionary and ecological entity, as well as a chance to study evolution in action.

Cox provides a guide to other research topics where an understanding of evolution is essential, including the development of invasion resistance by native communities. He considers evolution during lag times of invasion, which arise because different lifehistory characteristics are often required for dispersal and persistence in a particular environment. Cox also provides an introduction to coevolution between alien and native species, and to the effect of invasion on geographic speciation - although he makes it clear that this result is relatively minor compared with extinctions caused by invasions.

Little explicit attention is given to policy responses to species introductions, but Cox illustrates the need for greater consideration of evolutionary processes in risk analyses for alien species. In particular, he gives several examples of hybridization between wild species and related crops that have been genetically engineered for resistance to herbicides or insect pests. Transgenes have already flowed (or almost certainly will if they haven't already) from cultivated sorghum into Johnson grass, from oilseed rape into field mustard, from sunflower crops into wild sunflowers, and from wheat into jointed goatgrass. Wild species do not seem to suffer any reduction in fitness from incorporating some transgenes, contrary to the claims of many proponents of genetic engineering, so there are likely to be detrimental effects on native insects. Cox convincingly makes the case that evolution is central to any understanding of invasions, and that the analysis of risk is incomplete 